\title{
DIVERSITY MANAGEMENT AND SERVICE DELIVERY IN THE NIGERIAN AIRLINE INDUSTRY: A CUSTOMERS' PERSPECTIVE
}

\author{
By
}

\author{
AHMED, Mariam Ahuoiza \\ Department of Business Administration \\ Nasarawa State University, Keffi \\ ahuoiza17@yahoo.co.uk
}

\begin{abstract}
This study sought to assess the effect of diversity management on service delivery in the Nigeria aviation industry from a customers' perspective due to the observed problem of increasing customer complaints and migration. The study was restricted to customers of the aviation industry in Abuja Nigeria who served as the population of the study. The study adopted the survey research design while multiple regression technique was used to analyze the primary data collected for the study through a structured questionnaire. From a purposefully selected sample of 384 respondents, the study found that age diversity and gender diversity both have a positive and significant effect on service delivery in the Nigerian Aviation Industry. The study therefore recommends that the management of the aviation companies should make concerted efforts towards optimally managing the diversity of their workforce with a good blend of male and female across the younger and older generations in order to maximize service delivery outcomes for the companies and boost performance ultimately.
\end{abstract}

Keywords: Diversity Management, Gender, Age, Service Delivery, Customers, Abuja

c) 2020 the Author(s). Published by OASIS Journals. Open access under CC BY-NC-ND License

\section{Introduction}

The Nigerian aviation industry like every other industry has the responsibility of performing optimally in order to achieve its survival objectives and contribute its quota to the development of the nation's economy. Every firm or organization in a bid to optimize its performance, makes concerted efforts to enhance its product and service delivery so as to maximize customer's satisfaction and inspire repeat purchases that will allow for continued sales and profitability. Nigeria is often regarded as one of the most populous industrially developing nations in the world and richly endowed with abundant human and natural resources. However, most of 
the economic drawbacks of the nation may be attributable to the apparent inability of the organizations to perform optimally (Ugwuzor, 2014).

The aviation industry is a service centric industry whose customers interface with employees most of the time. These employees constitute the workforce of the firms and are therefore key to attaining the goals and objectives of the firms. The workforce will go a long way in determining customer experience towards service delivery of the firms. In line with this, Ukachukwu and Iherionhamma (2013) posited that no matter the type of organization, chances are that people's actions, inactions or counteractions could be a threat to its corporate performance, existence and ultimate survival. It has been opined that many modern work organizations have people of variegated demographic backgrounds working together as employees which may be a potential source of organizational conflict.

Again, diversity in the personality and other dimensions of diversity could also affect employee behavioural outcomes (Afolabi \& Omole, 2011). Thus, managers need to understand a wide range of behaviours to bring out the best in the distinctive competences of the workforce. Recognizing that the survival of their organizations is crucial to the economic health and instrumental to the strategic positioning of their countries in the comity of nations, managers who understand that the task of surviving in today's world is an enormous one, are most likely to ensure that the best persons are selected and maintained for the optimum performance of their organizations. If and when these 'best persons' come into the organizations, how well the various dimensions of their diversity are consciously managed leaves much to be desired. The proper management of workforce diversity therefore becomes an essential concern to strategic individuals and groups at the workplace. In the light of the present realities facing organizations today, it may be inferred that workforce diversity may create opportunities as well as pose challenges for the functioning and behaviour of organizations (Ugwuzor, 2014).

The researcher has observed from preliminary focus group discussions that customers of the Nigerian aviation sector have been increasing in intensity with high levels of switching intentions to competing service providers in the industry. This is a 
potentially disastrous situation for the firms and the industry at large. Previous studies such as Robb and Watson (2011), Dobbin and Jung (2011), Arokiasany (2013), Chatman, Polzer, Sigal and Neal (2014), Subhash and Kundu (2017), and Subhash and Archana (2017) among others assessed workforce diversity and outcomes for organisations, but the researcher could not find any recent study that assessed age and gender diversity as they affect service delivery in the aviation sector. However, this present study intends to close the gap in literature by scientifically examining the effect of Workforce Diversity Management on service delivery of firms in the Nigerian airline industry, with a view to bringing to the fore its implications for academics, managers and policy formulators as well as making suggestions that will help obtain the much desired optimum performance and service delivery for the firms. The objective of the study led to the formulation of the following null hypotheses for empirical testing:

Ho1 Gender diversity has no significant effect on service delivery in the Nigerian aviation sector

$\mathbf{H o}_{2}$ Age diversity has no significant effect on service delivery in the Nigerian aviation sector

The study was restricted to customers of the Nigeria aviation sector living in Abuja, Nigeria. This is because Abuja is the Federal Capital Territory of the country with customers moving to and from several destinations across the country and across the world. The study was a cross sectional one conducted in the year 2021. The study was also restricted to gender and age diversity which are two of the most obvious personality traits that customers can see when they approach employees.

\section{Conceptual Clarifications}

Traditionally, the term diversity has been widely used to refer to the demographic composition of a workforce. Some studies have looked at diversity using the compositional approach, otherwise known as Surface-level diversity (SLD) or demographic diversity, which refers to the extent to which a unit is heterogeneous on characteristics such as gender, ethnicity, religion, age, functional background, and 
organizational tenure (Tsui \& Gutek, 2000; Fajana, et. al, 2011). In addition to the surface-level composition of the group, deep-level diversity (DLD), otherwise seen as differences with respect to attitudes, personality, and values, has also been investigated (Barrick, et.al, 1998; Harrison, et. al, 2002; Thatcher, et. al. 2003).

To Daft (2008) Workforce diversity refers to a workforce made up of people with different human qualities or who belong to various cultural groups. The author regarded individual diversity to include people different from themselves along the dimensions such as social background. Workforce diversity as noted by Robbins and Judge (2011) acknowledges a workforce which comprised women and men. As the authors went on to observe, these individuals with variety of physical or psychological abilities. Diversity management is about finding ways to get the diverse contributions from employees.

In the words of Gitonga, Kamaara and Orwa (2016), workforce diversity refers to the acknowledgment, understanding, accepting, valuing, and celebrating differences among people with respect to age, class, ethnicity, gender, physical and mental ability, race, sexual orientation, spiritual practice, and public assistance status. In addition, Dessler, (2011) defines diversity as the variety or multiplicity of demographic features that characterize a company's workforce, majorly with respect to race, sex, culture, national origin, handicap, age, and religion. Some authors such as Bezrukova (2004) and Simons and Roland (2011) have explained that there are majorly two types of diversity; that is functional and demographic diversity.

Workforce Diversity Management is the ability of a manager to achieve success for an organization by making the best of use of the similarities and differences among employees in terms of age, cultural background, physical abilities and disabilities, race, ethnicity, religion, sex, as well as in terms of personality, values, attitudes, perception and cognitive style. Individuals who think towards deep level diversity are more likely to perceive themselves as similar, rather than dissimilar, to members of their workgroup on unobservable qualities (Liao, et. al, 2008). 
It may seem that the dynamics of diversity are especially salient in teams. This may be because it has been observed that where the level of face-to-face interaction is high, members often rely on one another to perform their tasks effectively (Tsui and Gutek, 2000). Indeed, empirical research in organizational and laboratory settings suggests that diversity make a difference for group outcomes and significantly affect the experiences of the individuals within the team (Harrison et.al, 2002; Jackson, et.al, 2003).

Powell (2011) defined gender as the physiological inference of a someone being either male or female, like expectations and beliefs regarding what kind of attitudes, behaviours, values, knowledge, skills, and interest areas are more suitable for or typical of one sex than the other. The study of gender diversity focuses on how individuals believe that males and females differ. These gender variations influence the manner in which individuals react to the behaviours of others in the work settings or any other group coalition. Gender diversities are visible in prejudice, stereotypes, and discrimination.

\section{Empirical Review}

Smith (2006) found that the proportion of women in top management jobs tends to have positive effects on firm performance, even after controlling for numerous characteristics of the firm and direction of causality. They use sample of 2500 Danish firms and found that presence of female in top management, firm performance varies from none to positive in relation, and those female directors, which are selected by staff, have positive effect on firm performance. Their results show that the positive effects of women in top management strongly depend on the qualifications of female top managers.

Dezso and Ross (2008) studied effectiveness of female as senior managers, using Tobin's $Q$ as performance yardstick. A positive association in firm performance and female participation below CEO level was found in innovative organizations. Their results showed potential competitive advantage for identification and development of female managerial talent. 
Similarly, Campbell and Vera (2008) studied the Spanish firms using panel data analysis, they found that gender has a positive effect on firm value and that the opposite causal relationship is not significant. They concluded that investors in Spain do not penalize firms, which increase their female board membership, and that greater gender diversity may generate economic gains as stock price shows a positive effect by announcement of female directors.

Adams and Ferreira (2009) found that female director have a significant impact on board inputs and firm outcomes. Their results showed that gender diverse boards allocate more effort to governance and monitoring because women are regular and punctual as compare to men but this thing not gives significant result that by increasing women ratio as directors will show positive association with performance measure.

Hussein and Kiwia (2009) examined the relationship between female board members and firm performance for a panel of 250 US firms over the years 2000 and 2006. On one hand, their results found no positive and significant relationship between performance measures of ROA, Tobin's Q ratio, gender influence and gender mix. On the other hand, the Shannon index, which measures the level of female representation inside the boardroom, showed positive and significant relationship between gender and firm value. Therefore, it is established that different measures may give different results, using the financial event study method.

Kang (2010) has found that investors generally respond positively to the appointment of women directors in Singaporean firms. This study did not only tests the theory of gender diversity in an Asian context but also examines whether investors react systematically to the different positions that women directors hold on corporate boards, a question that has received little attention in prior studies.

Jurkus (2011) investigated gender diversity among the top managers of Fortune 500 firms and its effect on agency costs. The study finds that firms with a greater percentage of female officer present lower agency costs but that the negative relation is not robust when considering the endogeneity of diversity. The results suggest that 
increasing diversity in management can have beneficial effects for firms where strong external governance is absent.

Ahern and Dittmar (2011) argued that by increasing female ratio as director stock value goes down leaving negative effect on firm performance in Norwegian firms, which is opposite to Campbell and Vera (2008). In their opinion female directors are not expert and senior as male directors are. Due to this diversity firm face losses and to fulfill its expenses company borrow from different sources, so operating costs increases, while profit and firm performance decreases.

Robb and Watson (2011) used longitudinal data of U.S new ventures to establish whether potential differences in performances of female and male owned firms vanishes if appropriate performance measures are used using 23 sampled US firms. Using ROA, Sharp ratio, univariate and multivariate test results confirmed that there is no difference in performance of female and male owned ventures.

Dobbin and Jung (2011) observed the effect of corporate board gender diversity on stock performance and concluded that the organization with board diversity shows negative or neutral results with different performance measure such as ROA, Tobin's $\mathrm{q}$ and cumulative stock returns. In such cases investors become biased and avoid to invest in firms having female directors which leads to a decline in stock prices.

Arokiasany (2013) observed that many organizations prefer to hire more of the male workers than the female workers because they are of the opinion that male workers have the ability to perform their jobs and can manage their jobs well. The general creativity and innovativeness of an organization may be enhanced by the combination of both male and female in the organization.

Chatman, Polzer, Sigal and Neal (2014) employed the self-categorization theory and tested hypotheses on the effects of an organization's demographic composition (Age, gender, etc.) and cultural emphasis on work processes and outcomes. Using an organizational simulation, their study found that the extent to which an organization emphasized individualistic or collectivistic values interacted with demographic composition to influence social interaction, conflict, productivity, and perceptions of 
creativity among 258 MBA students. Furthermore, the findings from the hierarchical regression suggested that the purported benefits of demographic diversity are more likely to emerge in organizations that, through their culture, make organizational membership salient and encourage people to categorize one another as having the organization's interests in common, rather than those that emphasize individualism and distinctiveness among members. The used data that are merely the perception of MBA students at major American Universities and therefore it suffers generalize ability problems.

Subhash and Kundu (2017) assessed whether perception of diversity varies significantly across gender and category and also tested whether employees' perception of diversity has relationship with perceived organizational performance. Primary data were collected through 402 questionnaires from 40 Information Technology (IT) companies in India. It was found that there is no significant effect of gender and category on receptivity to diversity and diversity management. The study also found that employee receptivity to diversity and diversity management has no significant effect on perceived organizational performance. The findings could be argued to be biased to the IT industry in India.

Subhash and Archana (2017) examined the relationship between employee perceptions of diversity (i.e. significance of diversity and diversity management, and value of diversity practices employed) and perceived organizational performance. It also attempts to examine whether the perceptions of diversity vary among employees from different diversity backgrounds (i.e. across gender and categories) in Indian IT industry. Primary data based on 402 respondents were analysed using statistical tools like factor analysis, correlations, analysis of variance, means, grand means, and regression. Results indicated that employees irrespective of their diversity backgrounds positively acknowledged diversity and diversity management.

However, all the previous studies were conducted in different locations and at different times using varying methodology. This study contributes to the body of academic knowledge by bridging the gap in research and providing the most recent findings and recommendations regarding the effect of diversity management on 
service delivery in the Nigerian aviation sector with particular reference to gender and age diversity.

\section{Theoretical Underpinning}

\section{Social Identity theory}

The Social identity theory (Tajfel, 1978) which underpins this study asserts that group membership can enhance ways individuals behave within the in-group, but often at the expense of those considered as those in the out-group. The theory is concerned with the existence of multiple identities, the variability of the degree to which people identify with a social group and the role of the social context in social identification (Deazux, 1993). This theory does not only explain one's self concept, but it also address the ways in which people view others. As group members are motivated to maintain their social identities, they tend to exhibit a favorable bias towards others who appear to have similar characteristics (Tajfel \& Turner, 2004; Turner \& Haslam, 2001). It is the quests for positive distinctiveness which social identity theory proposes that underlies many of the behavioural, evaluative and perceptual biases which are frequently observed in inter group contexts.

Individuals tend to develop a lot of identities as they move through the stages of their lives. They tend to define themselves in terms of their gender, religion, ethnicity, age, background or profession and "put on" different identities in different circumstances. In line with this thinking, Osaghae and Suberu (2005) observe that in Nigeria, by virtue of its complex web of politically salient identities and history of chronic and seemingly intractable conflicts and instability, competing groups tend to adopt exclusionary, winner-take-all strategies, with persons having crisscrossing and recursive identities of which the ethnic, religious, regional and sub-ethnic (communal) appear to be the most salient. Thus, members of a group can decide to identify themselves as 'religious' rather than 'ethnic', as individuals and groups may do from time to time, depending on the level and scope of conflict or uncertainty.

Strong group identification can predict whether discriminatory behaviour will or will not occur within a work setting particularly with regard to diversity. Mustapha (2005), 
ethno-linguistic and regional identities remain strong in Nigeria as private sector bureaucracies in the media, banks, the formal sector economy, and even civil society, continue to manifest considerable ethnic bias. Explanations of prejudice and discrimination focus on how being a member of a specific group helps to magnify one's sense of self-esteem.

\section{Methodology}

This study adopted the survey research design using a structured questionnaire as the main tool of data collection. The population of the study covers all customers of the aviation industry in Abuja which is unstated or infinite in Nature. The study therefore employed purposive sampling technique to select the respondents based on specific criteria set for the study. These criteria include: a) use of aviation sector for transportation services, b) previous interface or experience with employees of aviation sector, c) availability to take survey. The respondents were approached at the airport Abuja, Nigeria. However, a minimum sample size of 384 was adopted using the formula for sample size attainment from undefined population by the formula by Saunders et al (2009). The study adopted multiple regression analysis statistical technique to analyse the data for the study with a view to ascertaining the cause and effect relationship between the research variables using the following regression model:

$\mathrm{SD}=\beta_{0}+\beta_{1} \mathrm{GD}+\beta_{2} \mathrm{AD}+\mathrm{e}$

Where:

$\mathrm{SD}=$ Service Delivery (Dependent Variable)

$\mathrm{GD}=$ Gender Diversity

$\mathrm{AD}=$ Age Diversity

$\beta_{0}=$ Constant $/$ Intercepts

$\beta_{1}, \beta_{2}$ and $\beta_{3}=$ Parameters of determination

$\mathrm{e}=$ Margin of error

\section{Findings}

Based on the minimum sample size of 384, the researcher distributed 400 copies of the questionnaire. However, the returned and valid questionnaire copies were 352 . The 
352 returned and valid questionnaire copies were used for the data analysis of the study as follows:

Table 1: Descriptive Statistics for the Variables

\begin{tabular}{lrrr}
\hline Stats & SD & GD & AD \\
\hline Mean & 3.22 & 3.29 & 2.22 \\
p50 & 3 & 4 & 4 \\
Min & 1 & 1 & 1 \\
Max & 5 & 5 & 5 \\
Sd & 1.03 & 1.07 & 1.02 \\
N & 352 & 352 & 352 \\
\hline
\end{tabular}

Source: Researcher's Computation, 2021

Table 1 shows the descriptive statistics for all the variables used in this study. The mean and median value for Service Delivery (SD) is 3 and it indicates that the respondents on an average were undecided. The minimum and maximum value were 1 and 5 respectively. This values do not show presence of outliers as there is no much difference between the maximum and the minimum values. The standard deviation was found to be approximately 1 from the mean value.

For gender diversity (GD), the mean and median is approximately 3 and 4 respectively and the minimum and maximum values of 1 and 5 respectively. The standard deviation was found to be 1.07. For age diversity (AD), the mean and median is approximately 2 and 4 respectively and the minimum and maximum values of 1 and 5 respectively. The standard deviation was found to be 1.02 .

Table 2: Correlation Analysis

\begin{tabular}{lrrr}
\hline & SD & GD & AD \\
\hline SD & 1 & & \\
GD & 0.1861 & 1 & \\
AD & 0.2908 & 0.3364 & 1 \\
\hline
\end{tabular}

Source: Researcher's Computation, 2021

Correlation table 2 above shows a positive relationship between Service Delivery (SD) and gender diversity (GD) with a coefficient of 0.19; Service Delivery (SD) and age 
diversity (AD) with 0.29; gender diversity (GD) and age diversity (AD) with 0.34 ; They all exhibit positive relationships.

The correlation results indicate that there is no likelihood of multicollenearity problem associated with the data of the study as none of the correlation coefficients between the variables displayed any high relationship close to 1 , meaning that all the variables are not related.

Table 3: Extract of Regression Result

\begin{tabular}{lllrllll}
\hline $\begin{array}{l}\text { Independent } \\
\text { Variables }\end{array}$ & $\begin{array}{l}\text { Dependent } \\
\text { Variable }\end{array}$ & $\begin{array}{l}\text { Coef. } \\
(\beta)\end{array}$ & $\mathbf{T}$ & $\begin{array}{l}\text { P-value } \\
(\text { Sig. })\end{array}$ & F-Stat & $\begin{array}{l}\text { F-Stats } \\
\text { P- }\end{array}$ & Square \\
& & & & & & value & \\
\hline GD & SD & 0.135 & 0.117 & 0.000 & \multirow{2}{*}{116.5} & 0.000 & 0.695 \\
AD & SD & 0.012 & 0.292 & 0.000 & & & \\
\hline
\end{tabular}

Source: Researcher's Computation, 2021

The statistical decision rule of p- value states that the Null hypothesis should be maintained if $\mathrm{p}$-value is greater than alpha value (i.e. level of significance which is 0.05) otherwise it should be rejected while the Alternative hypothesis is adopted.

Table 3 shows that the regression model is fit to be used for the study as the F-stats is 116.5 with a p-value of 0.000 . The table also indicated the R-square which is used to determine the variability in the dependent (Service Delivery) variable that can be accounted for by a change in the independent variables. The R-square value of 0.695 (69.5\%) implies that the variability changes in Service Delivery to customers in Abuja that can be accounted for by the independent variables is approximately $69.5 \%$.

In table 3 also, it can be observed that the regression coefficient for gender diversity is 0.135 with p-value of 0.000 which is less than alpha value $(0.05)$ therefore, the null hypothesis is rejected. This implies that gender diversity has a positive and significant effect on Service Delivery of airline customers in in Abuja.

It can be further observed from Table 3 that the regression coefficient for age diversity is -0.012 with a p-value of 0.000 which is less than alpha value $(0.05)$ therefore, there is no sufficient reason to reject the null hypotheses. The study therefore rejects the null 
hypothesis which states that age diversity has no significant effect on Service Delivery to customers in Abuja. This implies that age diversity has a positive and significant effect on Service Delivery of customers in Abuja.

\section{Conclusions and Recommendations}

From the above findings, the study concludes that all the factors considered in this study affects service delivery to customers in Abuja. Both gender and age diversity was found to have a positive and significant effect on Service Delivery of consumers in Abuja Metropolis, age diversity was found to have a positive and no significant effect on Service Delivery to customers in Abuja.

This could mean that customers of the aviation industry consider gender to be a key factor in evaluating the quality of service delivery they have received. For instance it is said that women are more compassionate while men are factual and strong both giving out a vibe that customers can count on them.

Furthermore customers in the industry seem to see age as another key factor in evaluating quality of service delivery. It could be that the customers see that different age groups signifying younger or older generations have unique roles to play in delivering quality service like skills from the younger generation and experience from the older generation.

In line with the findings, the study therefore recommends that:

1. The management of airline companies in Nigeria should make concerted efforts to ensure the proper management of gender diversity in their recruitment and selection processes to ensure a right blend of the male and female genders so that customers can have a good feel of service delivery from the workforce.

2. The study recommends that managers of aviation companies in Nigeria should also make efforts to manage age diversity properly in their recruitment and selection processes so as to ensure a good blend of modern skills and experience that will work together towards optimizing service delivery quality and performance of the companies and sector ultimately. 


\section{References}

Afolabi, O.A. \& Omole, E.O.(2011) Personality Type and Workforce Diversity as Predictors of Ethical Behaviour and Job Satisfaction Among Nigerian Policemen, Current Research Journal of Social Sciences. 3 381-388.

Arokiasany, A. A. (2013). Literature Review on Workforce Diversity, Employee Performance and Organizational Goals: A Concept Paper. International Refereed Research Journal, IV(4), 58-63.

Daft, R.L. (2008) New Era of Management. 2nd ed, Thomson South-Western, Ohio.

Deazux, K. (1993) Reconstructing social identity, Personality and Social Psychology Bulletin, 19, 4-12.

Fajana,S., Owoyemi,O., Elegbede T. \& Gbajumo-Sheriff,M. (2011) Human Resource Management Practice in Nigeria, Journal of Management and Strategy, 2, 57-62.

Harrison, D. A., Price, K. H., Gavin, J. H., \& Florey, A. (2002) Time, Teams and Task Performance: Changing Effects of Surface and Deep-Level Diversity on Group Functioning, Academy of Management Journal , 451029 - 1045.

Jackson, E.S, Joshi A. \& Erhardt L.N. (2003) Recent Research on Team and Organizational Diversity: SWOT Analysis and implications, Journal of Management, $29801-830$.

Kang, S. H. (2010). Metrics and Models in Software Quality Engineering (2nd ed.). Canada: Pearson Education, Inc.

Mustapha, A.R. (2005) Ethnic Structure, Inequality and Governance of the Public Sector in Nigeria, CRISE Working Paper No. 18, Centre for Research on Inequality, Human Security and Ethnicity, University of Oxford, Oxford.

Osaghae, E.E. \& Suberu, R.T. (2005) A History of Identities, Violence, and Stability in Nigeria, CRISE Working Paper No. 6, Centre for Research on Inequality, Human Security and Ethnicity, University of Oxford, Oxford.

Powell, G. N. (2011). Women and Men in Management (4th ed.). California: Sage Publication, Inc.

Robbins, S.P. \& Judge, T.A. (2011) Organizational Behaviour. 14 $4^{\text {th }}$ ed. Pearson, New Jersey.

Simons, H. A. \& Roland, T. (2011). Administrative Behavior (3rd ed.). New York: Macmillan. 
Tajfel, H. \& Turner, J.C. (2004). The social Identity Theory of Intergroup behaviour. In Political Psychology: Key Readings(Eds, Jost, J.T and Sidanius, J.) Psychology Press, New York, pp.276-293.

Tajfel, H. (1978) Differentiation between social groups: studies in the social psychology of intergroup relations. Academic Press, New York:.

Thatcher, S.M., Jehn, K.A. \& Kanutto, E. (2003) Cracks In Diversity Research: Effects of Diversity Faultlines on Conflict and performance, Group Decision and Negotiation, 12 217-241.

Tsui A.S. \& Gutek, B.A. (2000) Demographic Differences in Organization, Lexington Books, New York.

Ugwuzor, M. (2011). Workforce Diversity Management in Nigerian Firms: The Interplay of Workforce Culture. Journal of Educational Research, 5(2), 1-8.

Ugwuzor, M. (2014). Workforce Diversity Management and Corporate Performance of Firms in Nigeria. International Journal of Business and Management Review, 2 (4), 36-46

Ukachukwu, C.C. \& Iheriohanma, E. B. J. (2013). The Effect of Cultural Diversity on Employee Productivity in Work Organizations in Port Harcourt, Nigeria, International Journal of Development and management Review, 832-49. 